\title{
Porf-2 Inhibits Neural Stem Cell Proliferation Through Wnt/ $\beta$-Catenin Pathway by Its GAP Domain
}

\author{
Guo-Hui Huang ${ }^{1}$, Xi-Tao Yang ${ }^{1}$, Kui Chen ${ }^{1}$, Jin Xing ${ }^{1}$, Lin Guo ${ }^{2}$, Liang Zhu ${ }^{1}$, \\ Hong-Jiang $\mathrm{Li}^{1}{ }^{1}$, Xin-Cai Li ${ }^{1}$, Sheng-Yi Zhang ${ }^{1}$ and Dong-Fu Feng ${ }^{1,3 *}$ \\ 'Department of Neurosurgery, Shanghai Ninth People's Hospital, Shanghai Jiao Tong University School of Medicine, \\ Shanghai, China, ${ }^{2}$ Neuroscience Division, Department of Anatomy, Histology, and Embryology, Shanghai Jiao Tong \\ University School of Medicine, Shanghai, China, ${ }^{3}$ Institute of Traumatic Medicine, Shanghai Jiao Tong University School of \\ Medicine, Shanghai, China
}

OPEN ACCESS

Edited by:

Niels Birbaumer,

University of Tuebingen, Germany

Reviewed by:

Shiva Tyagarajan

University of Zurich, Switzerland

$\mathrm{MuHe}$,

UCSF, USA

*Correspondence:

Dong-Fu Feng

fengdongfu@hotmail.com

Received: 18 November 2015 Accepted: 18 March 2016 Published: 31 March 2016

Citation:

Huang G-H, Yang $X-T$, Chen $K$, Xing J,

Guo L, Zhu L, Li H-J, LiX-C,

Zhang S-Y and Feng D-F (2016)

Porf-2 Inhibits Neural Stem Cell

Proliferation Through Wnt/B-Catenin

Pathway by lts GAP Domain.

Front. Cell. Neurosci. 10:85.

doi: 10.3389/fncel.2016.00085
Neural stem cell (NSC) proliferation and differentiation play a pivotal role in the development of brain, the plasticity of the brain network, and the repair for brain function in CNS diseases. The mechanisms regulating NSC behavior are not well elucidated. Previous studies showed porf-2 functions as a modulator in central nerve system development. We here show that porf-2, a conserved family of RhoGAPs, is highly and specifically expressed in NSCs. We also demonstrate that porf-2 inhibits the proliferation of NSCs in vivo and in vitro, but has no effect on NSC differentiation. We investigated which domain is required for the role of porf-2 on NSC proliferation. By using neurosphere formation and Edu assay we confirmed the GAP domain is necessary for its function. In addition, we surveyed a few classical pathways on NSC proliferation and found that porf-2 inhibits NSC proliferation by suppressing the $\beta$-catenin nuclear translocation. Taken together, we show for the first time that porf-2 inhibits NSC proliferation through Wnt/ $\beta$-catenin pathway by its GAP domain.

Keywords: neural stem cell, porf-2, cell proliferation, wnt/ $\beta$-catenin signaling, GAP

\section{INTRODUCTION}

In adult central nervous system (CNS), neural stem cell (NSC) proliferation and differentiation play a pivotal role in the development of brain, the plasticity of the brain network, and the repair for brain function in CNS diseases (Kempermann and Gage, 1999; Snyder et al., 2001; Koehl and Abrous, 2011; Mongiat and Schinder, 2011; Marin-Burgin and Schinder, 2012; Varela-Nallar and Inestrosa, 2013; Bond et al., 2015). The multipotent NSCs are found mostly in the dentate gyrus (DG) of the hippocampus and the subventricular zone (SVZ) of the lateral ventricles in adult (Alvarez-Buylla and Garcia-Verdugo, 2002; Zhao et al., 2008). The NSCs have the capacity for self-renewal and multipotential differentiation (Reynolds and Weiss, 1992). Once activated, NSCs develop into proliferating intermediate progenitor cells and the undifferentiated neuroblasts that will finally maturate into neurons, astrocytes or oligodendrocytes (Reynolds and Weiss, 1992; McKay, 1997; Gage, 2000; Zhao et al., 2006; Ming and Song, 2011). The new born cells are able to integrate into the existing neural circuitry and contribute to different brain functions (Deng et al., 2010). Moreover, NSC transplantation is also a promising therapeutic strategy in several CNS diseases, including brain and spinal cord injuries, stroke, epilepsy, and neurodegenerative disease 
(Rossi and Cattaneo, 2002; Muller et al., 2006; Nakamura and Okano, 2013; Burns and Thapar, 2014; Aertker et al., 2015; Rolfe and Sun, 2015; Tong et al., 2015). Thus elucidating the molecular mechanism of NSC behavior will help us understand brain development and provide a platform for future NSCs' clinical application (Shimazaki, 2003; Selden, 2008).

To coordinate the proper progression of NSC proliferation and differentiation with preserving the stem cell pool, there should be a balance between the self-renewal and maintenance of NSCs and the differentiation. NSC proliferation and differentiation are a dynamic process and regulated by a variety of intrinsic and extrinsic factors including growth factors, cell surface receptors, signal transduction molecules, and transcription factors (Zhao et al., 2008; Bond et al., 2015). Several signaling molecules regulate NSC proliferation and differentiation including PTEN, Wnt, Notch, bone morphogenetic proteins (BMP), growth and neurotrophic factors, neurotransmitters, and transcription control (Suh et al., 2009; Ming and Song, 2011; Hsieh, 2012; Schwarz et al., 2012; Faigle and Song, 2013). However, our understanding of NSC behavior is still limited.

Preoptic regulatory factor-2 (Porf-2), also named as Cross GTPase-activating protein (CrossGAP)/Vilse, was first discovered from the preoptic area of the hypothalamus of the castrated male rat (Nowak, 1990, 2003). Nowark et al. found that porf- 2 is widely expressed in diverse tissues including the CNS and peripheral tissues (Hu and Nowak, 1994; Nowak, 1997, 2003). In the CNS of the rat, it is highly expressed in the hippocampus, hypothalamus, and cerebral cortex ( $\mathrm{Hu}$ and Nowak, 1994; Nowak, 2003). In drosophila, Hu et al. (2005) reported that porf-2 can directly interact with Roundabout (Robo) and regulate midline crossing of axon through Rac1dependent cytoskeletal changes, which plays a significant role in the axon development of CNS. Similarly, Lundstrom et al. (2004) also reported that porf- 2 is required for midline repulsion in CNS of the drosophila. In a recent study of neuronal development in mice, Lim et al. (2014) reported that porf-2 is involved in dendritic spine formation through Racl pathway. These data indicated diverse function of porf-2 in CNS. Additionally, in a study of porf- 2 in NSCs, Ma et al. (Ma and Nowak, 2011) found that porf- 2 may play a role in the proliferation of $\mathrm{C} 17.2$ cells, a mouse cerebellar multipotent cell line. But the detail function and mechanism of porf- 2 on NSC proliferation and differentiation has not been elucidated yet.

Porf-2 has three domains: WW domain, Myosin Tail Homology 4 (Myth4) domain, and GTPase activating proteins (GAP) domain. The WW domain can bind to the Robo as reported (Lundstrom et al., 2004; Hu et al., 2005). The function of Myth4, which may provide a link between an actin-based motor protein and the microtubules cytoskeleton, is not yet fully understood (Kerber and Cheney, 2011). The GAP domain is predicted to transform Rac1/cdc42-GTP status to GDP status which is inactivated (Tcherkezian and Lamarche-Vane, 2007). But it still lacks of adequate evidence. Taken together, up to now, the function of the three domains is still rarely reported.

In the present study, we report that porf-2 is highly expressed in NSCs. We also demonstrate that porf- 2 inhibits the proliferation of NSCs in vivo and in vitro. In addition it is the GAP domain that contributes to this phenomenon through the classical wnt/ $\beta$-catenin pathway. Taken together, we show for the first time that porf-2, a conserved family of RhoGAPs, inhibits NSC proliferation through wnt/ $\beta$-catenin pathway by its GAP domain.

\section{MATERIALS AND METHODS Isolation and Culture of Hippocampus NSCs}

All procedures involving the use of laboratory animals were approved and monitored by the Animal Care Committee of the Shanghai Jiao Tong University School of Medicine. NSCs were isolated from newborn mice at postnatal day 0 or 1 as described previously (Yang et al., 2014). In brief, the newborn mice were terminated by decapitation and hippocampus were carefully dissected, pooled together in a $5 \mathrm{ml}$ conical tube containing $1 \mathrm{ml}$ dissection buffer $\left(2 \mathrm{M} \mathrm{NaCl}, 1 \mathrm{M} \mathrm{KCl}, 1 \mathrm{M} \mathrm{MgCl}_{2}, 155 \mathrm{mM}\right.$ $\mathrm{NaHCO}_{3}, 1 \mathrm{M}$ Glucose, $108 \mathrm{mM} \mathrm{CaCl}$, $100 \mathrm{U} / \mathrm{ml}$ Penicillin/100 $\mu \mathrm{g} / \mathrm{ml}$ streptomycin) and sliced into small pieces. After $5 \mathrm{~min}$ of settling, the supernatant was gently removed and the remaining tissue was incubated with $1, \mathrm{ml}$ of $0.25 \%$ trypsin $/ 0.03 \%$ EDTA at $37^{\circ} \mathrm{C}$ for $30 \mathrm{~min}$ followed by one time washing with Dulbecco's modified Eagle medium-DMEM/F12 (1:1) medium. After gentle trituration with a $1 \mathrm{ml}$ pipette, the cell suspension was settled for $5, \mathrm{~min}$, and carefully transferred to a new $15 \mathrm{~mL}$ tube. After centrifugation at $500 \mathrm{~g}$ for $5 \mathrm{~min}$ at room temperature (RT) and removal of the supernatant, the cell pellets were resuspended in $1 \mathrm{ml}$ of complete NSCs medium, DMEM/F12 (1:1) medium supplemented with $1 \times$ B27 (Gibco, 17504), $1 \times$ N2(Gibco, 17502-048), plus $100 \mathrm{U} / \mathrm{ml}$ penicillin, $100 \mu \mathrm{g} / \mathrm{ml}$ streptomycin (Gibco, 15140-122), and basic fibroblast growth factor (bFGF) ( $20 \mathrm{ng} / \mathrm{ml}, \mathrm{R} \& \mathrm{D})$, epidermal growth factor (EGF; $20 \mathrm{ng} / \mathrm{ml}$, R\&D). NSCs were cultured for 4-5 days in the complete NSCs medium and formed neurospheres. When they reached 100$150 \mu \mathrm{m}$ in diameter, the NSCs spheres were dissociated using $0.25 \%$ trypsin at $37^{\circ} \mathrm{C}$ and re-passaged. The experiments were performed using passage 3-6 neurospheres. Depending on the type of experiment, 1 to $2 \times 10^{5}$ single cells in $2 \mathrm{ml}$ of complete NSCs medium were plated into each well of a 6-well plate or 0.5$1 \times 10^{3}$ cells in $500 \mathrm{ul}$ of complete NSCs medium were plated into each well of a 24 -well plate.

\section{Differentiation and Proliferation of NSCs}

For the differentiation experiment, the dissociated single NSCs suspension was plated in 24-well cell culture chambers, which had been coated by poly-D-lysine (Sigma-Aldrich, P7886) and $6 \mu \mathrm{g} / \mathrm{mL}$ laminin (Sigma-Aldrich, L4544). Then the cells were cultured for 7 days in the differentiating medium composed of NeurobasalA (Gibco, 10888) supplemented with $1 \times$ B27 and $1 \%$ FBS. The differentiated cells were fixed for $30 \mathrm{~min}$ at room temperature in $4 \%$ paraformaldehyde (PFA) prior to immunostaining using antibodies specific for $\beta$-tubulin III (Tuj1; 1:1000, beyotime, AT809), glial fibrillary acidic protein (GFAP; 1:3000, Millipore, AB5806), and staining of nuclei with 4',6-diamidino-2-phenylindole (DAPI). Each experiment average 
percentage of positive cells was calculated on randomly selected six fields of photograph.

To determine the proliferation of NSCs, Edu labeling was performed using a Click-iT ${ }^{\circledR}$ EdU Alexa Fluor ${ }^{\circledR} 647$ Imaging Kit (Molecular Probes, life technology) according to the manufacturer's instructions. Briefly, primary neurospheres were dissociated into single cells and the dissociated single NSCs cell suspension was plated onto laminin-coated chamber slides. After 4 days culture in NSC complete medium, Edu labeling solution was added into the medium at final concentration of $10 \mu \mathrm{M}$. After $30 \mathrm{~min}$ incubation, attached NSCs were fixed with 4\%PFA for $30 \mathrm{~min}$, permeabilized, and then incubated with Click-iT ${ }^{\circledR}$ reaction cocktail $30 \mathrm{~min}$ at room temperature, protected from light. Chamber slides were then mounted with mounting medium with DAPI, and imaged with a confocal laser scanning microscope. Average percentage of positive cells was calculated on randomly selected six fields of photograph from slice. The Edu positive cells were counted by manually.

\section{Immunofluorescence}

NSC spheres or the differentiated single neuronal cells on chamber slides were processed for histology as above. For brain slice immunofluorescence, after fixation with 4\%PFA perfusion of mice, the brain slices were made for $30 \mu \mathrm{m}$ per slice. Both the cells and the brain slice were blocked in $1 \times$ PBS plus 0.3\% Triton X-100 and 10\% Normal Donkey Serum (Jackson ImmunoResearch, 122346) for $60 \mathrm{~min}$ at RT, and followed by incubation at $4{ }^{\circ} \mathrm{C}$ for overnight in primary antibodies (diluted in blocking buffer). After 3 times washes (10 min for each wash) in $1 \times$ PBS plus $0.1 \%$ Triton $\mathrm{X}-100$, the sections or cells were incubated in the fluorescence-conjugated secondary antibodies (1:500 dilution in $1 \times$ PBS) plus DAPI for $1 \mathrm{hr}$ at RT. After 3 times washes, the chamber slides were then mounted with mounting medium and imaged.

Following primary antibodies were used: rabbit anti-Nestin (marker for NSPCs 1:400, Abcam), goat anti-Doublecortin (Dcx, marker for neuronal precursor cells, 1:100, Santa Cruz, sc8066), rabbit anti-Ki67 (1:200, Thermo scientific, RB-1510), rabbit anti$\beta$-catenin (1:500, Cell Signaling Technology, 8480). Cell nuclei were stained with DAPI. Images were taken using a fluorescence microscope and analyzed with Image J.

Appropriate secondary antibodies were used as follows: donkey anti-mouse IgG conjugated with AlexaFluor 488, donkey anti-rabbit IgG conjugated with AlexaFluor 594, donkey anti-goat IgG conjugated with AlexaFluor 488, donkey antirat IgG conjugated with AlexaFluor 594, donkey anti-rabbit IgG conjugated with AlexaFluor 488, donkey anti-rabbit IgG conjugated with AlexaFluor 594. All of secondary antibodies were purchased from Molecular Probes (Life Technologies), and diluted 1:500 before use.

\section{Domain Deleted DNA Constructs}

Porf-2 gene was amplified from hippocampal cDNA by PCR. Then the porf- 2 gene was digested by Xbal1/Not1 enzyme and constructed to Plv-IRES-ZsGREEN1 vector. As for the domain deleted plasmid, the $\Delta$ ww-porf-2 (65-99 amino acid deleted), $\Delta$ Myth4-porf-2(717-902 amino acid deleted), $\Delta$ GAPporf-2 (914-1099 amino acid deleted) were also constructed by PCR and ligased to Plv-IRES-ZsGreen vector. All the plasmids were packaged into lentivirus. The viruses were generated by cotransfection of two helper plasmids (pVSVG and pCMV $\triangle 89$ ) into the packaging cell line HEK293T at a ratio of 5:6:6 pLvxporf-2:pVSVG:pCMV $\Delta 89$. Viruses were harvested $48 \mathrm{~h}$ after transfection by collecting the medium from transfected cells and stored at $-80^{\circ} \mathrm{C}$.

\section{Western Blotting}

Hippocampal regions from mice at different ages were dissected, homogenized, and solubilized at $4^{\circ} \mathrm{C}$ in Cell lysis buffer (P0013, beyotime) supplemented with $1 \mathrm{mM}$ PMSF, $50 \mathrm{mM} \mathrm{NaF}$, $1 \mathrm{mM} \mathrm{Na3VO} 4$ and protease inhibitor. NSCs were collected, homogenized, and solubilized in the same buffer. The total protein lysates were separated by SDS-PAGE and analyzed by western blotting with anti-GAPDH (1:5000, Sigma-Aldrich, G8795), mouse anti-Nestin (1:1000, Cell Signaling Technology, 4760), goat anti-Doublecortin (1:1000, Santa Cruz, sc8066), antip-PTEN(1:1000, Cell Signaling Technology, 9554s), anti-PTEN (1:1000, Cell Signaling Technology, 9188s), anti- $\beta$-actin (1:5000, Thermofisher scientific, MA5-15739) anti-p-Akt (1:1000, Cell Signaling Technology, 4060s), anti-Akt (1:1000, Cell Signaling Technology,2920s), p-mTOR (1:1000, Cell Signaling Technology, 5536s), anti-mTOR((1:1000, Cell Signaling Technology, 2972s), PI3K((1:1000, Cell Signaling Technology, 5569s), p-PI3k(1:1000, Cell Signaling Technology, 4228s), $\beta$-catenin (1:1000, Cell Signaling Technology, 8480), anti-NICD (1:1000, Cell Signaling Technology, 4147p), anti-HA (1:1000, Cell Signaling Technology, 2367s), anti-Histon H3 (1:3000, Cell Signaling Technology, 4499), anti-tuj1 (1:1000, beyotime, AT809), anti-porf-2 (1:1000, Santa Cruz Biotechnology, 87186). HRP-conjugated anti-rabbit, anti-mouse and anti-goat secondary antibodies (A0208, A0216 and A0181) were from beyotime. Analysis of the data was performed using NIH ImageJ software. The mean density of each band was normalized to actin or GAPDH signal in the same sample.

For the nuclear and cytoplasmic protein separated experiment, the protein in nucleus and cytoplasm were extracted following the Nuclear and Cytoplasmic Protein Extraction Kit (P0028, beyotime), then the same as above, the nuclear and cytoplasmic protein were analyzed by western blotting with indicated antibody.

\section{ShRNA Viral Production and Infection}

The sequence of porf- 2 shRNA are as follows: shRNA1: CCC TTGATTCCTCATGAAT, ShRNA2: CTGCGAGATCTTCAA GCTA shRNA3: CAAAGTGACACAGCACATA. Negative Control: TTCTCCGAACGTGTCACGT. All the shRNAs were constructed into PLKO.1 vector and the lentivirus were packaged as mentioned above.

The shRNA1 was also constructed to pAKD-CMV-bGlobinmCherry-H1-shRNA vector. Packages of AAV9-shRNA viruses were provided by Obio Technology, Shanghai, China. Viral titers were $2.4 \times 10^{12}$ particles/mL for AAV-ShRNA1, $1.3 \times 10^{13}$ particles/mL for AAV-ShRNA-control. 
For intracranial viral infection, $1 \mu \mathrm{l}$ of concentrated AAVshRNA was injected into the hippocampal DG area of P1 mice by stereotaxic injection. Six weeks after viral injection, the infected mice were sacrificed and processed for immunostaining as described above. The coordinates for the dentate gyrus were as follows: AP, $1 \mathrm{~mm}$; ML, $1 \mathrm{~mm}$; and DV, $1.5 \mathrm{~mm}$.

\section{Statistical Analysis}

All experiments were performed at least three times in triplicate. The results are presented as mean \pm SEM. Statistical differences were determined by Student's $t$-test for two-group comparisons or ANOVA followed by Tukey's test for multiple comparisons among more than two groups.

\section{RESULTS}

\section{Porf-2 is Highly and Specifically Expressed in Hippocampal NSCs In vivo and In vitro}

To identify whether porf-2 is expressed in NSCs, we cultured primary hippocampal NSCs. After 5 days culture, NSCs grows into neurosphere stage (Figure 1A). Most of cells in such neuroblasts were immunostained positive for nestin, a common NSC maker (Figure 1A). Then we performed immunofluorescence on the cultured NSC neurosphere and single NSC with porf- 2 and nestin antibody. Immunofluorescence assay with these antibodies revealed that endogenous porf- 2 is localized in the nucleus and fiber of the NSCs, as indicated by its colocalization with nestin (Figure 1B). Consistent with in vitro study, porf- 2 colocalized with nestin in the DG area of the hippocampus (Figure 1C). Moreover, porf-2 was also expressed in $\mathrm{GFAP}^{+} /$Sox $-2^{+}$cells, further confirming its expression in NSCs (Figure S1). While, interestingly, there is no localization of porf-2 with DCX, a progenitor cell maker (Figure 1D). This indicted that porf- 2 is specifically expressed in the NSCs.

To examine the expressing pattern of porf-2 during development of NSCs, we performed western blot on hippocampus tissue lysate throughout early postnatal development. As shown in Figure 1E, porf-2 gradually increased during development and in a time-dependent manner. Also the protein level of nestin and DCX gradually decreased (Figure 1E), which is consistent with the fact that in the early stage there are more NSCs in DG area. Then we analyzed the correlation between porf- 2 and nestin expression and the result showed that there was a negative correlation $\left(p<0.05, r^{2}=\right.$ 0.5785 ; Figure 1F), indicating that porf- 2 correlated with nestin expression during the development. Meanwhile porf-2 had no correlation with Tuj1 $\left(r^{2}=0.078, p>0.05\right.$; Figure 1F). The contrary expression pattern indicted porf- 2 may have a negative role on the nestin expression. Together these data demonstrate porf-2 is specifically expressed in the NSCs in vitro and in vivo and may have a negative correlation with nestin expression.

\section{Knockdown of Porf-2 Promotes NSC Proliferation, But Has No Effect on NSC Differentiation In vitro}

We have described porf-2 expression pattern. Next, we explored its function on NSC behavior. Firstly, we performed knockdown of porf-2 in mouse hippocampal NSCs by using lentiviralmediated shRNA delivery. As shown in Figure 2A and Figure S2, all the shRNAs have a high knockdown efficiency, especially the shRNA3, about 61\% knockdown in protein level (Figure 2A). Thus we use shRNA3 to investigate the effect of porf-2 on NSCs for all the subsequent testings.

To assess the role of porf- 2 on NSC proliferation, we performed neurosphere formation assay as described in methods. Four days after the lenti-shRNA infection, all NSC neurospheres were GFP-postive in both groups (Figure 2B). By quantifying the size of multipotent neurosphere, we found that knockdown of porf-2 resulted in larger size neurosphere than those of controls (Figures 2B,C). Moreover, the percentage of large size neurosphere in shporf-2 group is higher in comparison to control (Figure 2C). These data indicated that knockdown of porf-2 can promote NSC proliferation. The effect of porf-2 on NSC proliferation was further measured by the Edu assay. Consistent with the results in neurosphere assay, knockdown of porf- 2 showed higher number of Edu positive cells than the control cells, which means NSC proliferation was enhanced by porf-2 knockdown (Figure 2D). Together, these results indicate that knockdown of porf-2 has a promoting effect on NSC proliferation.

To study the possible effect of porf- 2 on NSC differentiation, we induced the cell differentiation in NSC differentiation medium for 7 days after lenti-shRNA infection. The cells in single cell layer were then fixed prior to routine histological process. The NSC differentiation into mature neural cells was further verified by immunostaining, using antibodies of neural cell lineage markers, including Tuj1 (neurons), GFAP (astrocytes) and the cell nuclei were labeled with DAPI (Figure 2E). The percentage of Tuj1 and GFAP labeled cells was calculated and no significant difference was observed between the two groups (Figure 2E). Overall, our results suggest that knockdown of porf-2 can improve NSC proliferation but has no role on NSC differentiation.

\section{Porf-2 Inhibits NSC Proliferation In vitro}

To further demonstrate the role of porf- 2 on NSC proliferation, we overexpressed porf-2 in NSCs. The overexpression of porf-2 was confirmed by WB (Figure 3A). By using the neurosphere assay, we measured the diameter of NSC sphere and found that overexpression of porf-2 can significantly reduce the diameter of NSC sphere compared to control (Figures 3B,C). In the Edu assay, as shown in Figure 3D, $\sim 34 \%$ NSCs in control and about $28 \%$ NSCs in porf- 2 overexpression group were Edu positive, confirming that overexpression of porf-2 decreased NSC proliferation. Altogether, our results suggest that overexpression of porf-2 inhibits NSC proliferation in vitro.

\section{Porf-2 Inhibits NSCs Proliferation through Its GAP Domain}

As porf-2 has three domains: WW, Myth4, and GAP domain, we tried to find out which domain is required in the NSC proliferation. Next, we created three domain deleted plasmids of porf-2. The construct pattern was shown in Figure 4A. Our western blot result suggested that the three plasmids were successfully constructed (Figure 4A). In agreement with 
A
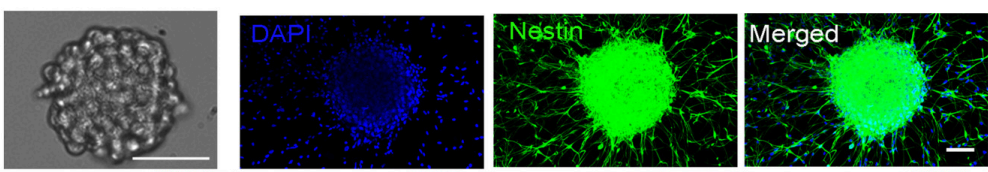

B
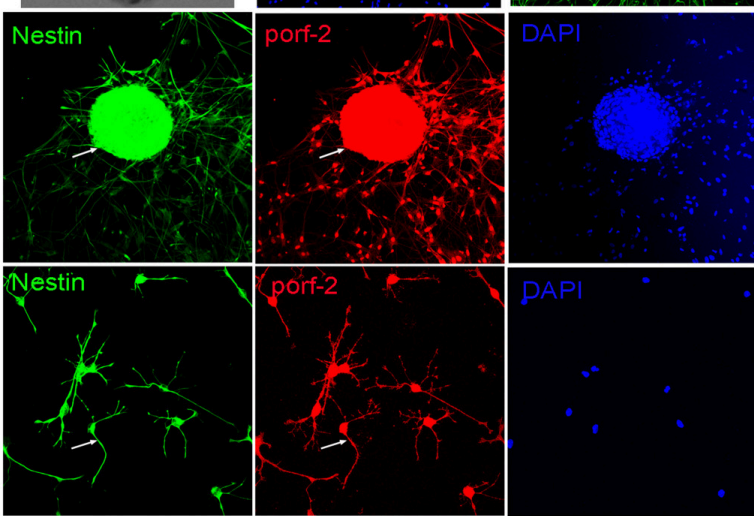

Merged

C
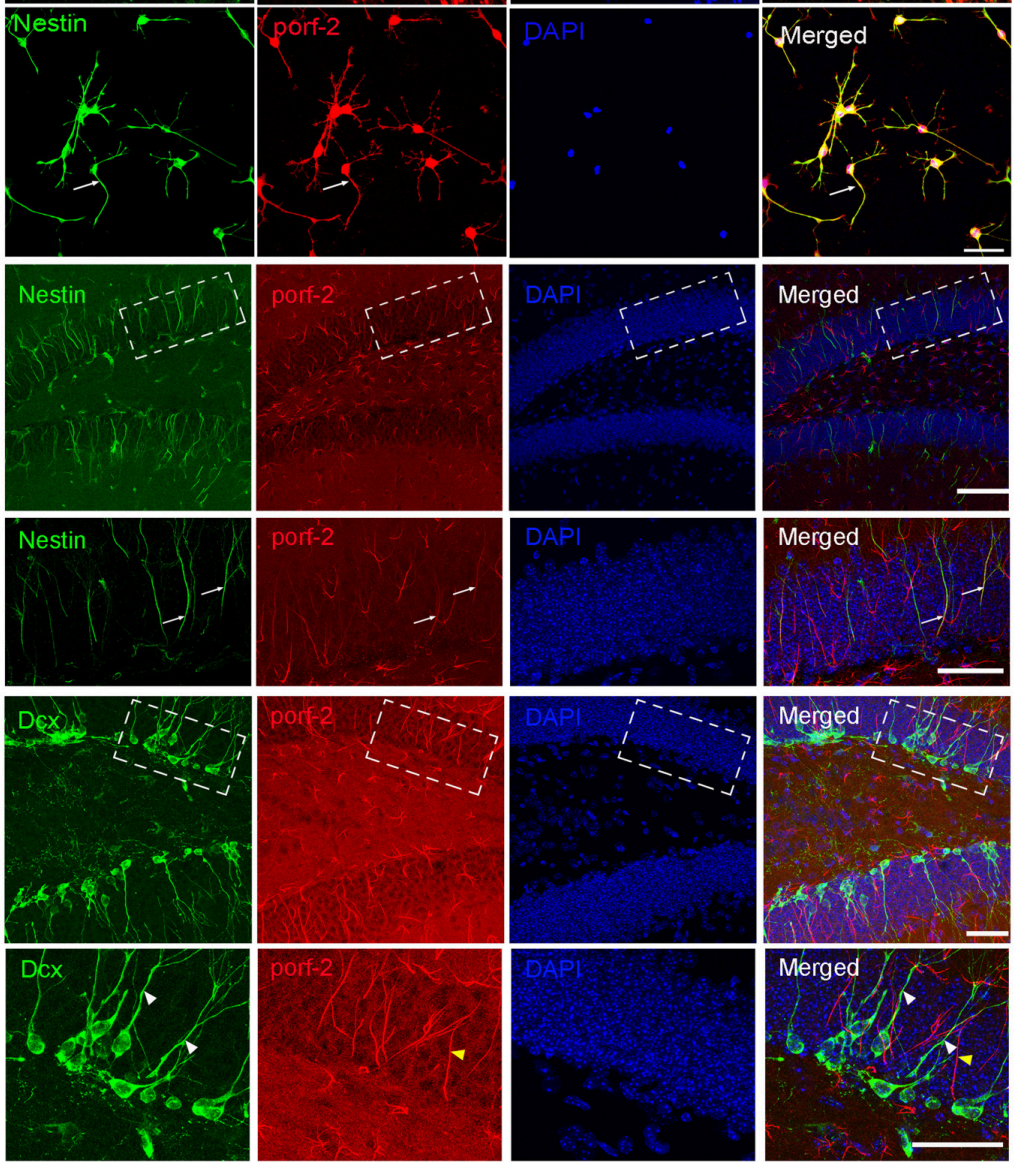

E Nestin $=-0$
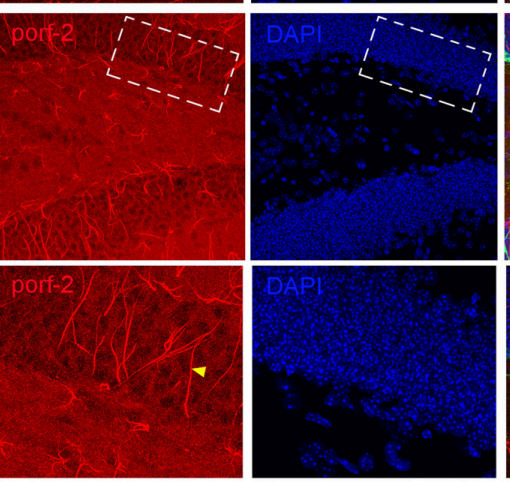

Merged
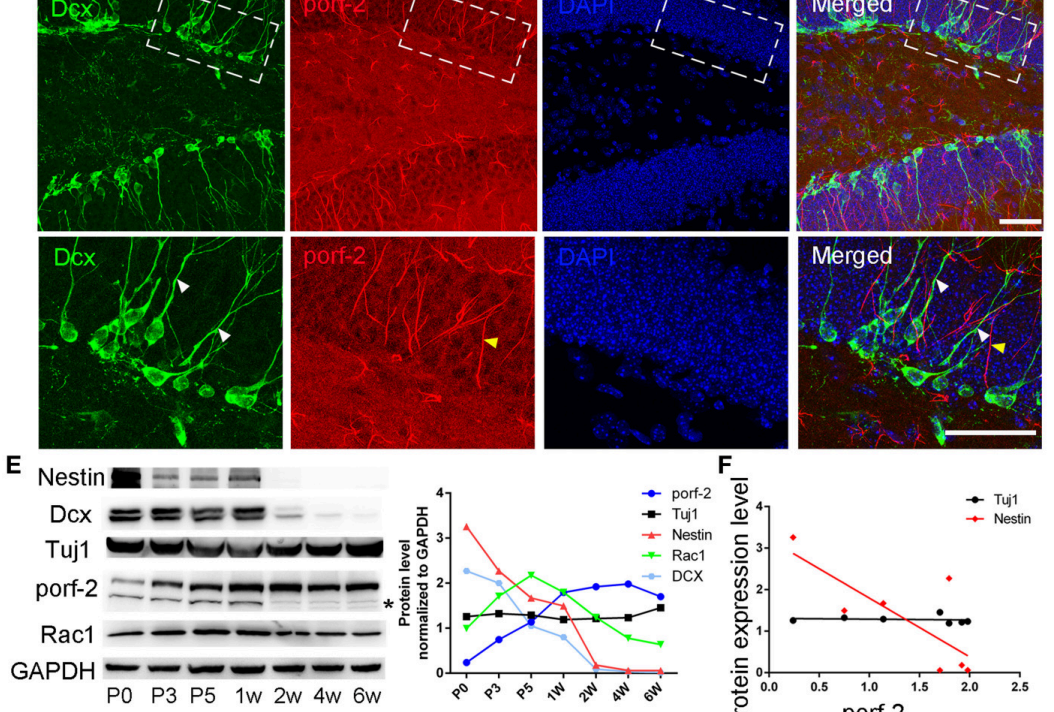

$\mathbf{F}$

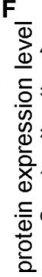

$\rightarrow$ Tuj1
$\rightarrow$ Nestin

FIGURE 1 | Porf-2 is highly and specifically expressed in hippocampal NSCs in vivo and in vitro. (A) Representative images of neurosphere formation after culture for 4-5 days. Identification of NSC neurosphere by immunofluorescence with nestin antibody. Scale bar: $50 \mu \mathrm{m}$. (B) Colocalization of porf-2 with nestin in neurosphere and single NSC visualized by immunofluorescence (indicated with white arrow). Scale bar: $50 \mu \mathrm{m}$. (C) Expression and colocalization of porf-2 with nestin visualized by immunolabeling with indicated antibody in DG area of hippocampus of brain slice. The boxes in upper panel are shown at higher magnification in lower panels. Whtie arrow indicates the colocalization of porf-2 with nestin. Scale bars: $100 \mu \mathrm{m}$ in the upper panel and $50 \mu \mathrm{m}$ in the lower panel. (D) No colocalization of Porf-2 with DCX in DG area. The boxes in upper panel are shown at higher magnification in lower panels. White arrowhead indicates DCX positive cell. Yellow arrowhead indicates porf-2 positive cell. Scale bars: $50 \mu \mathrm{m}$ in both upper and lower panels. (E) The expression pattern of porf-2, nestin, DCX, Tuj1 and Rac1 proteins were analyzed by western blotting of hippocampal lysates at postnatal day 0, 3, 5; 1, 2, 4, and 6 week. The same blot was probed with anti-GAPDH antibody as a loading control. The symbol * indicates non-specific signal in western blot analysis. Quantification of porf-2, nestin, DCX, Tuj1, and Rac1 protein level at indicated time. (F) The expression level of porf- 2 was correlated with nestin (red dots) but not tuj1 (black dots) during development. (Red dot, $r^{2}=0.5785, p<0.05$. Black dot, $r^{2}=$ $0.078, p>0.05)$ 
A

porf-2

GAPDH

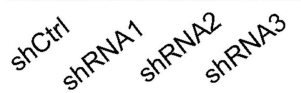

B

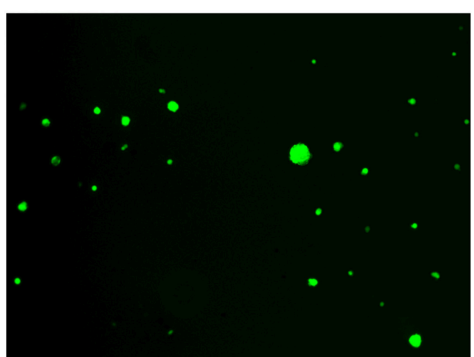

C

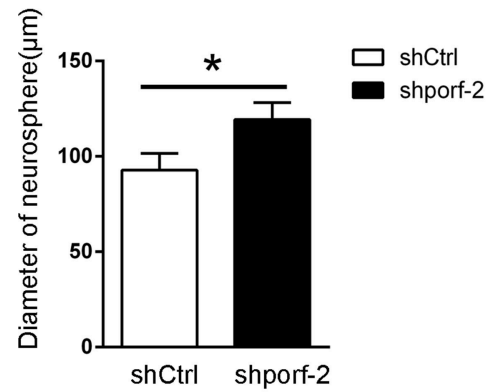

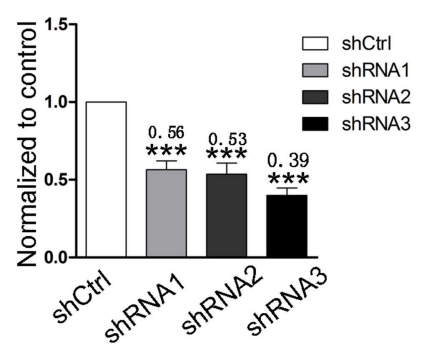

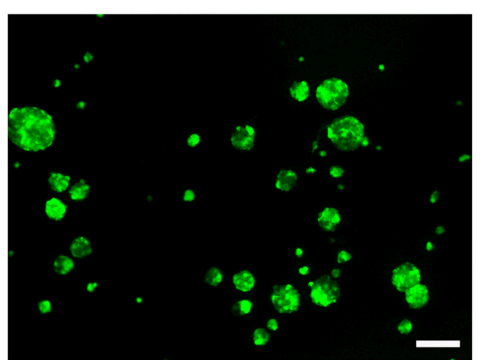

shporf-2

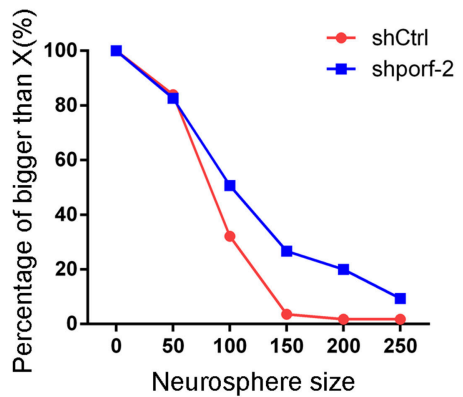

D
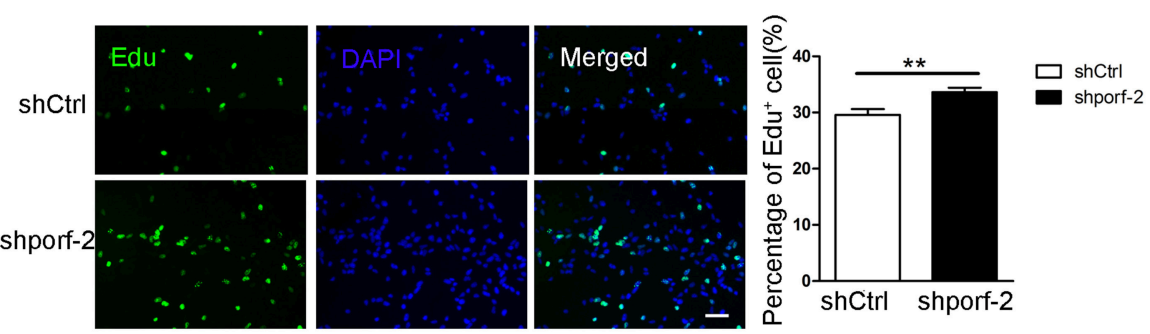

E
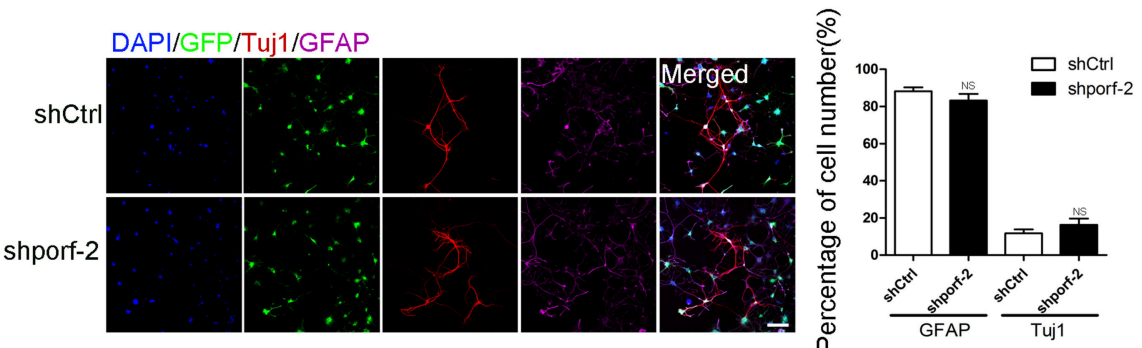

FIGURE 2 | Knockdown of porf-2 increased NSC proliferation but had no effect on NSC differentiation. (A) Knockdown of porf-2 by lenti-shRNA infection was confirmed by immunoblot analysis in NSCs. ${ }^{* *} P<0.001$ vs. shCtrl. (B) Representative image of neurosphere after 4 days culture in lenti-shCtrl and lenti-shporf- 2 group. Scale bar: $200 \mu \mathrm{m}$. (C) Comparison and Quantification of the diameter of NSC spheres between shCtrl and shporf-2 group after 4 days lentivirus infection. The percentage of different neurosphere size was quantified (right panel). Data are mean $\pm \operatorname{SEM}(n=4) .{ }^{*} p<0.05$. (D) Representative image of Edu positive cells in shCtrl and shporf-2 group. Quantification of the percentage of Edu positive cell number in each group. The number of Edu positive cells is normalized to the total cell number. Scale bar: $100 \mu \mathrm{m}$. Data are mean \pm SEM $(n=4) .{ }^{* *} p<0.01$. (E) Confocal images showing the Tuj1 and GFAP positvie cell after 7 days differentiation of NSCs in each group. Quantification of the percentage of Tuj1 and GFAP positive cell number in shCtrl and shporf-2 group. The number of Tuj 1 or GFAP positive cells is normalized to the total cell number. Scale bar: $100 \mu \mathrm{m}$. Data are mean \pm SEM $(n=4)$. NS: no significant difference $P>0.05$. 
A

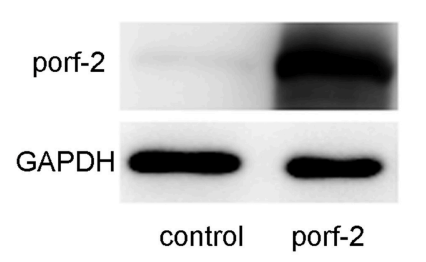

B

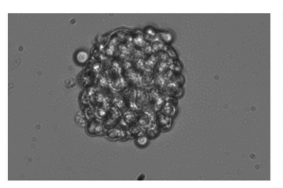

control

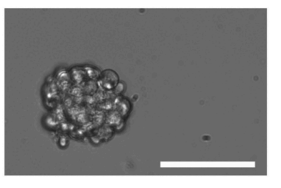

porf-2

C
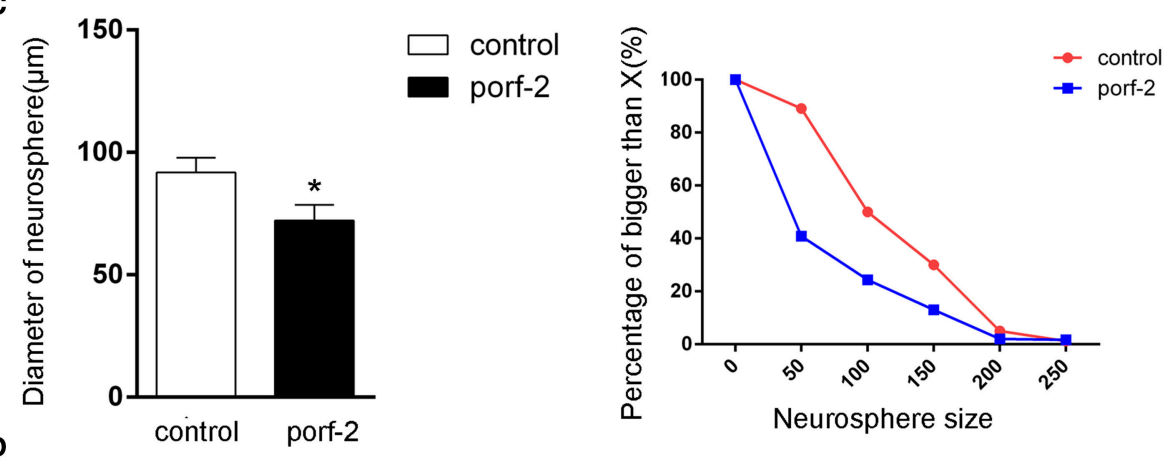

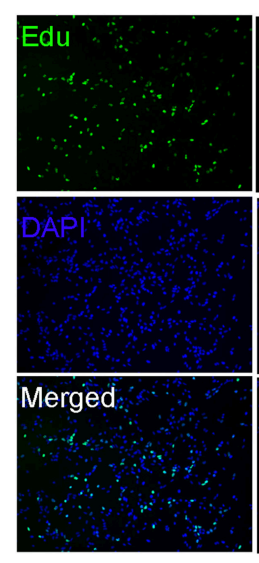

control

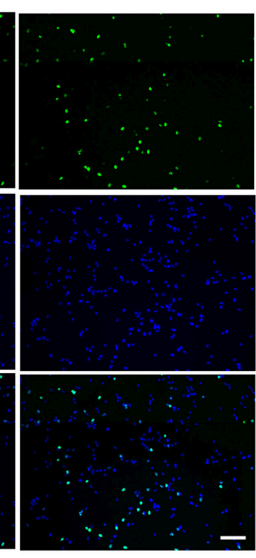

porf-2

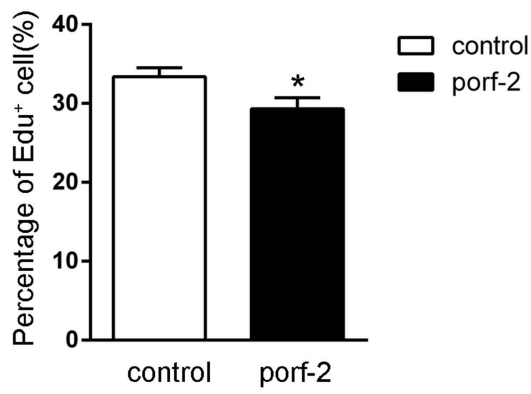

FIGURE 3 | Porf-2 inhibits NSC proliferation in vitro. (A) Confirming the overexpression of porf-2 protein by immunoblot. (B) The neurosphere morphology in control and porf-2 overexpression group. Scale bar: $50 \mu \mathrm{m}$. (C) Quantification of the diameter of neurosphere in each group. Data are mean \pm SEM ( $n=3$ ). (D) Representative image of Edu positive cells in each group. The total NSC number was counted by DAPI. Quantification of the percentage of Edu positive cell number in each group. Scale bar: $100 \mu \mathrm{m}$. Data are mean $\pm \operatorname{SEM}(n=4) .{ }^{\star} P<0.05$.

our result above, overexpression of porf-2 showed smaller neurosphere phenotype compared to control (Figures 4B,C). Similarly, overexpression of $\Delta$ ww-porf- 2 and $\Delta$ Myth4porf-2 showed smaller neurosphere phenotype compared to control, which is consistant with porf-2 overexpression. While interestingly, the diameter of neurosphere in $\triangle$ GAP-porf-2 group was back to control level, which indicated that the GAP domain is the functional domain of porf- 2 in NSC proliferation (Figures 4B,C).

In agreement with the above-mentioned neurosphere formation assay, overexpression of porf-2, $\Delta$ ww-porf-2, or $\Delta$ Myth4-porf-2 showed lower percentage of Edu positive cells in Edu assay, and $\triangle$ GAP-porf-2 showed no difference in comparison to control (Figures 4C,D). The result indicated that $\triangle$ GAP-porf-2 lost its function on NSC proliferation.
In other words, the GAP domain is required for porf-2's function on NSC proliferation. Above all, porf-2 inhibits NSC proliferation and the GAP domain plays an essential role in this process.

\section{Porf-2 Inhibits the NSC Proliferation through Wnt/ $\beta$-Catenin Pathway}

As is well-known, there are a few classical pathways involved in NSC proliferation: PTEN/PI3k-Akt, Akt-mTOR, Notch, and Wnt/ $\beta$-catenin pathway (Liu and Niswander, 2005; Egeland et al., 2015). To understand the mechanism of how porf-2 inhibited NSC proliferation, we surveyed above pathways. As shown in Figure 6A, p-PTEN/PTEN, p-PI3K/PI3K, p-Akt/Akt protein level remained unchanged after porf-2 overexpression, indicating that porf-2 had no effect on PTEN/PI3K/Akt pathway. Then we 
A
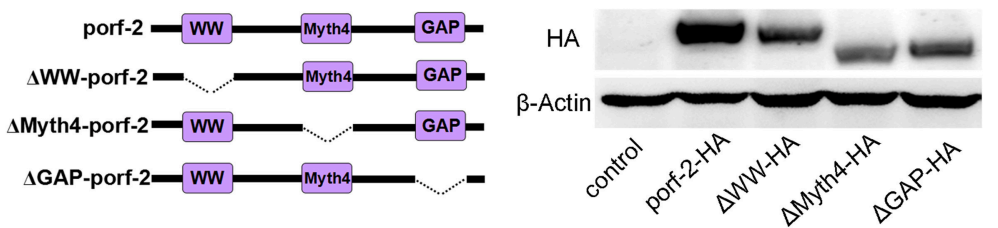

B
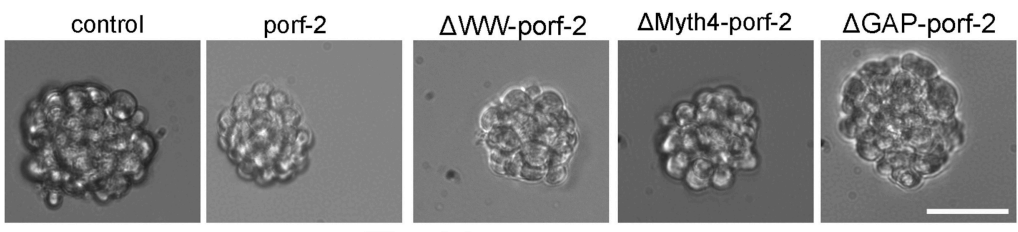

C
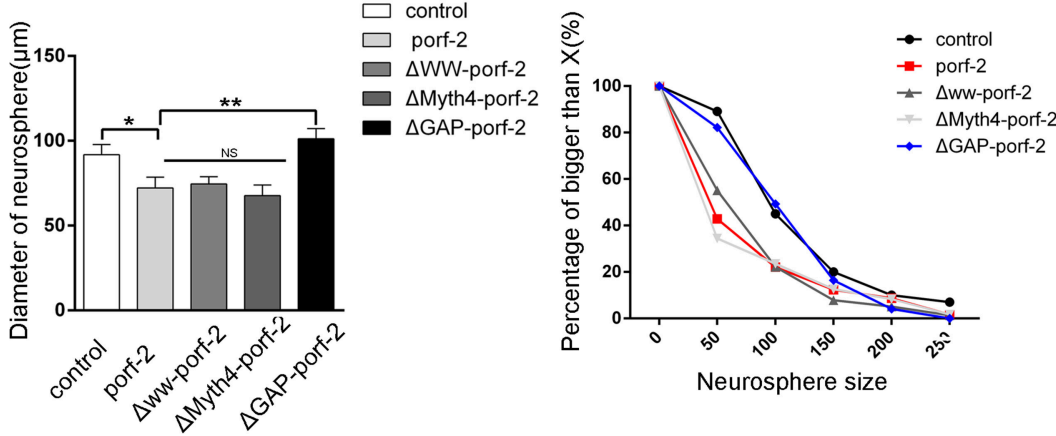

D
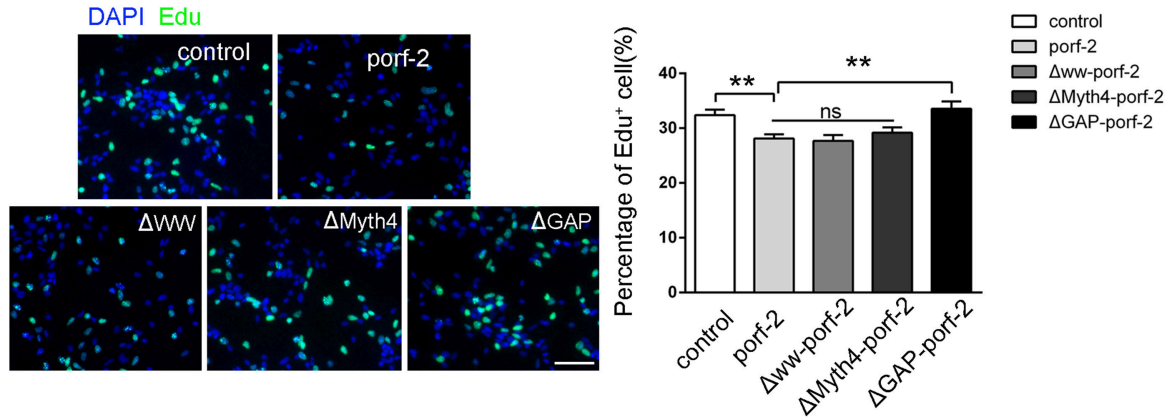

FIGURE 4 | The GAP domain is required for the porf-2's function on NSC proliferation. (A) The construct pattern of the domain deleted plasmid. Verification of domain deleted plasmid by immunoblot. The same blot was probed with $\beta$-actin antibody as a loading control. (B) The morphology of neurosphere in different groups. Scale bar: $50 \mu \mathrm{m}$. (C) Quantification of neurosphere size in each group. ${ }^{*} p<0.05,{ }^{* *} p<0.01$. (D) Representative images of Edu positive cells in indicated group. Quantification of the percentage of Edu positive cell number in each group. Scale bar: $50 \mu \mathrm{m}$. Data are mean $\pm \operatorname{SEM}(n=5) .{ }^{\star *} P<0.01$.

found that although p-mTOR protein level had a slight decrease, it showed no significant difference with control (Figure 5A). We also checked the Notch and Wnt/ $\beta$-catenin pathway and found that there was no difference in NICD and $\beta$-catenin protein level between overexpression of porf-2 and control group (Figure 5A). Similar results were obtained when porf- 2 was knock down in NSCs (data not shown).

Given the fact that $\beta$-catenin plays a pivotal role in Wnt $/ \beta$-catenin pathway by entering into nucleus to mediate NSCs proliferation, a process known as $\beta$-catenin nuclear translocation (Kahn, 2014; Sun and Hevner, 2014), we analyzed the effect of porf- 2 on the cellular distribution of $\beta$-catenin. The cytoplasm and nucleus proteins were separated as indicated by GAPDH and HistoneH3 (Figure 5B). Interestingly, we found that though there was no change of $\beta$-catenin in the cytoplasm, the protein level of $\beta$-catenin in nucleus significantly decreased after porf- 2 overexpression, which suggested porf- 2 decreased the translocation of $\beta$-catenin to nucleus (Figure $5 \mathbf{B}$ ). Consistent with the western blot result, we observed that $\beta$ catenin mostly expressed in cytoplasm instead of nucleus after porf-2 overexpression by immunoflourence (Figure 5C). Also we investigated the effect of mutant porf- 2 plasmids on $\beta$ catenin nuclear translocation. As shown in Figure 5D, the protein level of $\beta$-catenin in nucleus significantly decreased in $\Delta$ ww-porf-2 and $\Delta$ Myth4-porf-2, which is consistant with porf-2 overexpression, while the protein level of $\beta$-catenin in nucleus in $\triangle$ GAP-porf-2 group was back to normal. This suggested that $\triangle$ GAP-porf-2 domain is responsible for porf2 's effect on $\beta$-catenin nuclear translocation (Figure 5D). Based on these findings, we propose that porf- 2 can decrease the nuclear translocation of $\beta$-catenin through its GAP domain. 
A

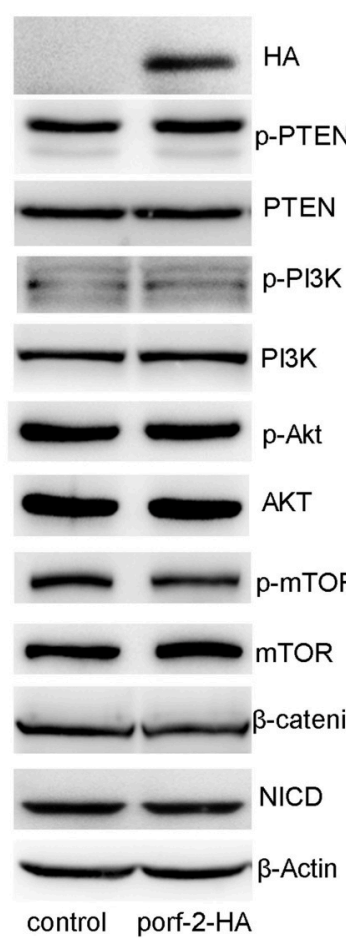

control porf-2-HA
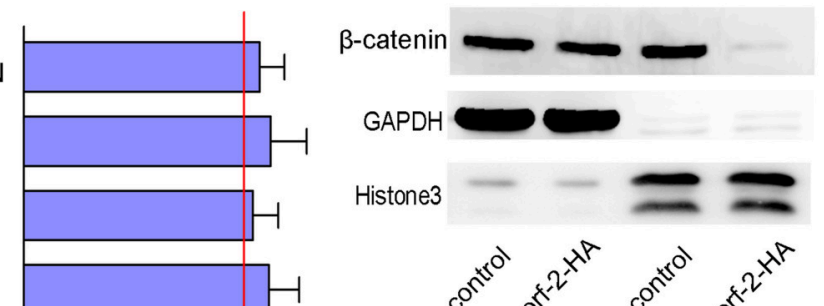

Histone3

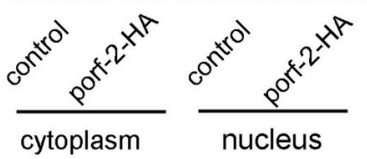

$\beta$-catenin

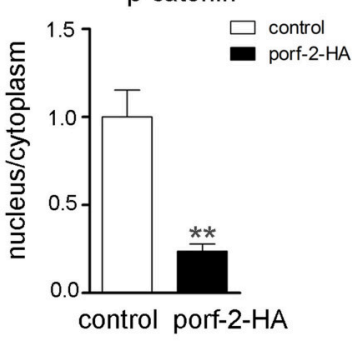

control porf-2-HA

C

DAPI/GFP/B-catenin/Nestin
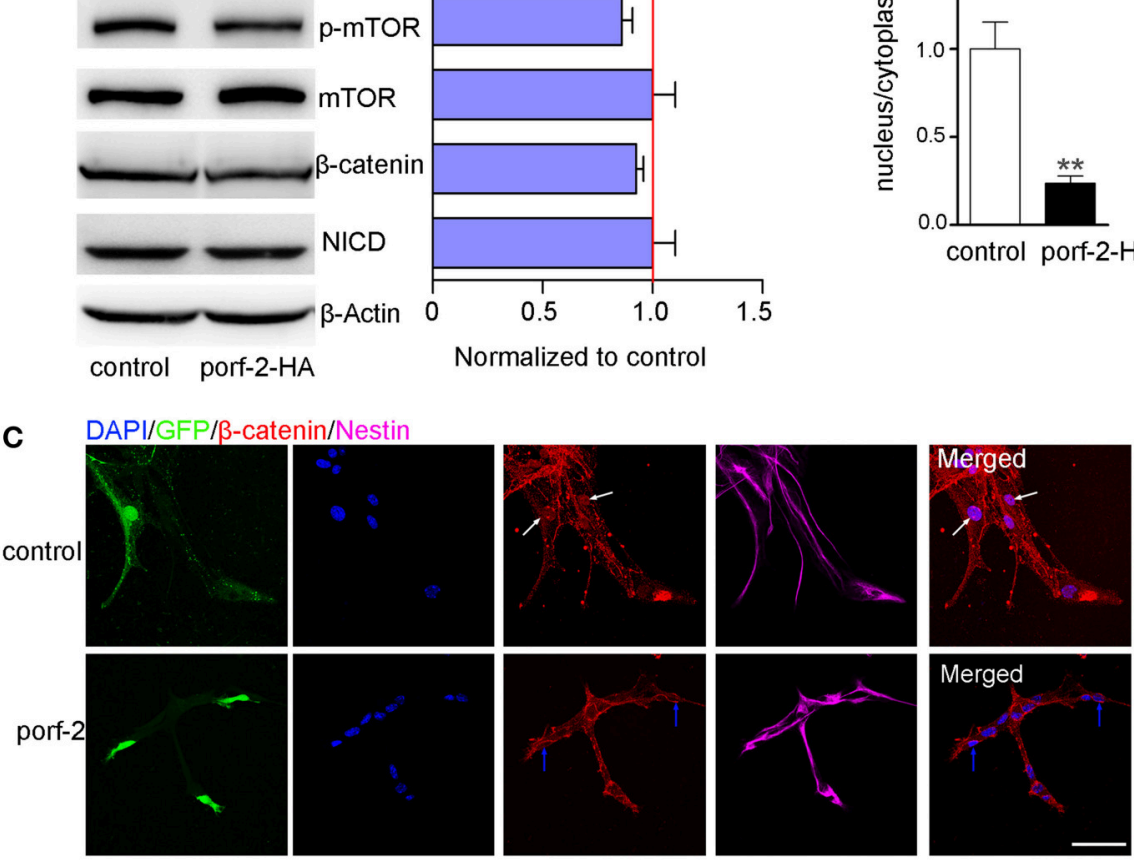

D
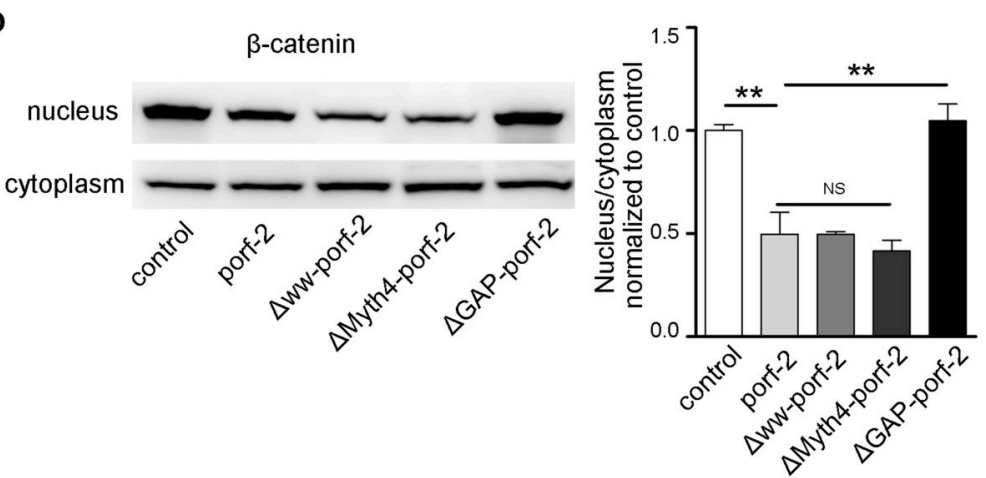

$\square$ control

$\square$ porf-2

$\Delta$ ww-porf-2

- $\Delta$ Myth4-porf-2

- $\triangle$ GAP-porf-2

FIGURE 5 | Porf-2 inhibits NSC proliferation through wnt/ $\beta$-catenin pathway. (A) The expression and quantification of p-PTEN, PTEN, p-PI3K, PI3K, p-Akt, Akt, p-mTOR, mTOR, NICD, and $\beta$-catenin protein in control and porf-2 overexpression group. Data are mean $\pm \operatorname{SEM}(n=3)$. $\beta$-actin was used as a loading control. (B) The expression and quantification of $\beta$-catenin protein in cytoplasm and nucleus in control and porf-2 overexpression group. GAPDH and HistoneH3 were used as loading controls for protein in cytoplasm and nucleus respectively. ${ }^{* *} p<0.01$. (C) Confocal microscopy image of $\beta$-catenin expression in NSCs after lentivirus infection. White arrow indicated the expression of $\beta$-catenin in nucleus in control group. Blue arrow indicated the expression of $\beta$-catenin in nucleus in porf-2 overexpression group. Scale bar: $50 \mu \mathrm{m}$. (D) The expression and quantification of $\beta$-catenin protein in cytoplasm and nucleus in different groups. Data are mean \pm $\operatorname{SEM}(n=3) .{ }^{*} p<0.01$ 
A

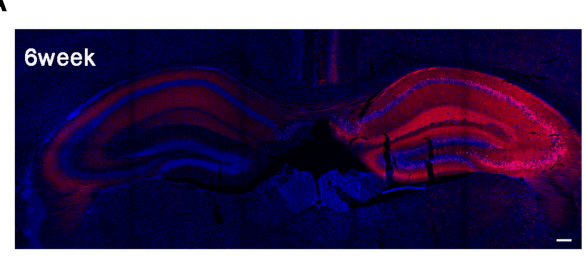

B

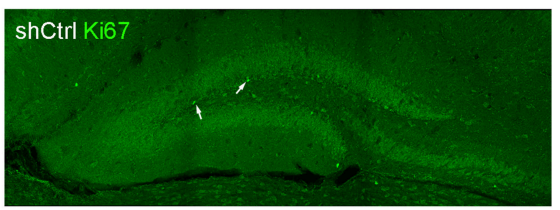

shporf-2 Ki67
C

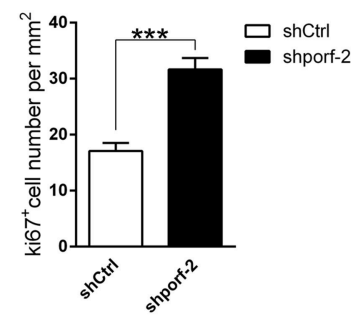

D

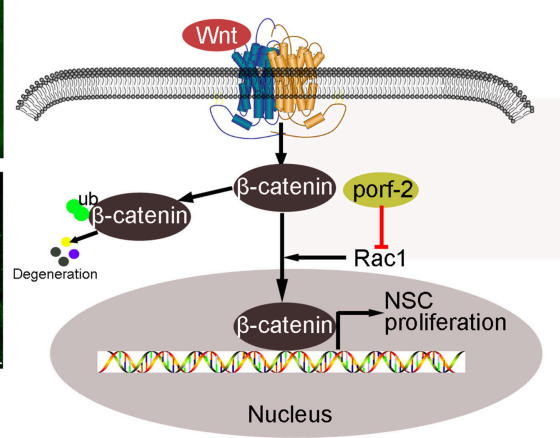

FIGURE 6 | Knockdown of porf-2 promotes NSC proliferation in vivo. (A) The expression of AAV-shRNA indicated by mcherry after 6 weeks infection. Scale bar $100 \mu \mathrm{m}$. (B) The ki67 staining in brain slice in each group. The white arrow indicated ki67 positive cell. Scale bar: $100 \mu \mathrm{m}$. (C) Quantification of ki67 positive cell number in each group. Data are mean $\pm \operatorname{SEM}(n=8)$. ${ }^{* \star} P<0.001$. (D) Schematic drawing demonstrating a previously uncharacterized mechanism for porf-2 inhibits NSC proliferation through wnt/ $\beta$-catenin pathway by its GAP domain.

\section{Knockdown of Porf-2 Promotes NSC Proliferation In vivo}

To further investigate the function of porf-2 on NSC proliferation in vivo, we took advantage of AAV-mediated shRNA delivery. At postnatal day 1 , the AAV-shRNA was injected into the DG area of unilateral hippocampus. Six weeks later, the whole ipsilateral hippocampus area was infected with the AAV virus, indicated by red fluorescence (Figure 6A). To assess the effect of shporf2 on NSC proliferation, the infected brain slices were stained with an antibody against the proliferation maker ki67. Next we calculated the ki67 positive cell number in the DG area and found that the number of ki67 positive cells was higher in shporf2 group in comparison to control (Figures 6B, C). Our results suggest that knockdown of porf-2 can promote NSC proliferation in vivo.

\section{DISCUSSION}

Our study is the first to show that porf-2 is highly and specifically expressed in hippocampal NSCs. It also palys a pivotal role in NSC proliferation in vivo and in vitro. Moreover, our findings clearly indicate that porf- 2 inhibits NSCs proliferation through its GAP domain by Wnt/ $\beta$-catenin pathway (Figure 6D).

Previous studies showed porf-2 functions as a key modulator in axon and dendrite spine development. In CNS, porf- 2 is expressed in different regions of brain, hippocampus, cerebral cortex, hypothalamus, and so on (Hu and Nowak, 1994; Nowak, 1997, 2003). However, whether or not it is expressed in hippocampal NSCs and its expression pattern are not elucidated.
Here in this study, we took advantage of immunoflourenscence and western blot to first demonstrate porf- 2 is highly expressed in NSCs and its expression increases in a time-dependent manner. These findings prompt us to further investigate its function on NSC behavior.

NSCs are a unique population of cells that exhibit stem cell properties, including self-renewal, i.e., production of a large number of progeny, and multipotency, i.e., differentiation into the three CNS neural lineages (Louis and Reynolds, 2005). Because NSCs have the ability to support neurogenesis throughout adulthood, they have been viewed as a renewable source of neural precursors for regenerative transplantation in various CNS diseases (Horner and Gage, 2000; Teng et al., 2002). Increasing evidence suggests that NSCs go through a process of self-renewal, proliferating, and differentiating into the appropriate lineage when inflammatory damage or injury occurs in the nervous system (Pluchino and Martino, 2008). In the present study we demonstrate porf- 2 can inhibit NSC proliferation and knockdown of porf- 2 promotes NSC proliferation, which provides us a new insight into neurogenesis. Unexpectedly, our study showed that porf-2 did not affect NSC differentiation, that is to say, it isn't involved in NSC differentiation into neuron or astrocyte. The possible reason is that porf-2 is specifically expressed in activating NSCs but not the later stages indicated by DCX, which means once the NSCs go into differentiation stage, porf-2 is not expressed any more. Thus, porf-2 cannot exert its functions.

Ma et al. (Ma and Nowak, 2011) has recently reported that knockdown of porf-2 induced increased proliferation and druginduced apoptosis through p53/p21 pathway in C17.2 cell. But 
Ma's report on NSC proliferation is based on an artificial stem cell line (Ma and Nowak, 2011). In addition, the porf-2 protein reported in Ma's study is a $65 \mathrm{KD}$ peptide (Ma and Nowak, 2011), not the full-length porf-2, which has a few transcripts. Different with Ma's study, we focused on the full length of porf2 gene, which encodes a $130 \mathrm{kd}$ protein. Instead of studying stem cell line, we paid attention to cultured hippocampal NSCs and observed knockdown of porf- 2 significantly increased the size of neurosphere and the number of Edu positive cells. The results indicated that downexpression of porf- 2 promoted NSC proliferation. Consistent with the down-expression phenotype, overexpression of porf- 2 decreased the size of neurosphere and the percentage of Edu positive cell number. Moreover, AAVshRNA-porf-2 injection increased the ki67 positive cell number in DG area, which further confirmed the function of porf- 2 in vivo assay.

It is known that porf- 2 has three conserved domains. The WW domain of porf- 2 was reported as a binding domain which can bind to member receptor robo and scaffold protein CNK2 to transduce signal pathway to mediate axon and spine development (Hu et al., 2005; Lim et al., 2014). The MyTH4 domain has been identified as a conserved domain in the tail domains of several different unconventional myosins for intracellular trafficking, cell division, and muscle contraction (Lu et al., 2014). The GAPs, which enhance the intrinsic GTPase activity, leading to the inactive state of the GTPase, involved in multiple cellular process including NSC proliferation (Dasgupta and Gutmann, 2005; Tcherkezian and Lamarche-Vane, 2007). But as for porf-2, which domain is necessary for its function on NSCs is not clear. In our in vitro neurosphere formation and Edu assay, we found that the full-length-porf-2, $\Delta$ ww-porf-2, the $\Delta$ Myth4-porf- 2 all showed a smaller size of neurosphere and lower percentage of Edu positive cell number, while the $\Delta$ GAP-porf-2 showed no difference compared to control. Furthermore, compared to fulllength-porf-2 group, the $\triangle \mathrm{GAP}$-porf-2 showed a larger size of neurosphere and higher percentage of Edu positive cell number. The data showed that the GAP domain deleted porf- 2 lost its inhibitory function on NSC proliferation.

The basic action of NSC proliferation is mediated by several signal pathways: PTEN/Akt, Akt/mTOR, Notch, and $\mathrm{Wnt} / \beta$-catenin pathway (Suh et al., 2009). In our study, we found that porf- 2 overexpression didn't affect the protein expression of p-PTEN, p-Akt, p-mToR, which implied that porf-2 may not be involved in PTEN/Akt/mTOR signaling pathway. The Notch signaling pathway is a highly conserved cell signaling system involved in NSC proliferation and differentiation (Yoon and Gaiano, 2005; Louvi and ArtavanisTsakonas, 2006; Ables et al., 2011; Homem et al., 2015). Ligand proteins binding to the extracellular domain of Notch induced proteolytic cleavage and release of the Notch intracellular domain (NICD), which translocated to the nucleus to activate transcription of downstream target genes to mediate NSC proliferation and differentiation (Louvi and Artavanis-Tsakonas, 2006). We examined the NICD protein level and found that porf-2 overexpression didn't affect the NICD expression, which suggested that porf- 2 didn't affect the Notch signaling pathway.
Although these above-mentioned signaling pathways aren't involved in porf- 2 's action on NSC proliferation, we demonstrated porf-2 inhibits NSC proliferation through the $\beta$-catenin pathway. In present study, we found that overexpression of porf- 2 didn't affect the total $\beta$-catenin protein level, but reduced the nuclear $\beta$-catenin level. By using immunofluorescence, we also confirmed that porf-2 overexpression suppressed $\beta$-catenin nuclear translocation. Porf-2 has been reported to mediate midline axon guidance by inactivating Rac1 in the developing stage (Lundstrom et al., 2004; $\mathrm{Hu}$ et al., 2005). It was reported that Racl can mediate $\beta$-catenin nuclear translocation (Esufali and Bapat, 2004; Upadhyay et al., 2008; Wu et al., 2008; Bosco et al., 2010). Moreover porf-2 is a RhoGAP, which can inactivate Racl as reported (Lundstrom et al., 2004; Hu et al., 2005; Lim et al., 2014). Thus we propose that porf- 2 can mediate $\beta$-catenin nuclear translocation through inactivating Rac1 by its GAP domain. To test this hypothesis, we deleted the GAP domain and found that the $\triangle$ GAP-porf2 lost its function on $\beta$-catenin nuclear translocation. To further confirm our hypothesis, we performed the Edu assay to verify the effect of Rac1 DN on NSC proliferation. And both the Rac1 DN and porf-2 overexpression showed a lower percentage of Edu positive cell number in comparison to control (Figure S3), suggesting Rac1 DN and porf-2 overexpression showed the same phenotype in NSC. Thus, our work revealed an uncovered mechanism through which porf-2-induced proliferation impairment takes place by the modulation of Wnt/ $\beta$-catenin signaling through its GAP domain, which may inactivate Racl and result in the suppression of $\beta$-catenin nuclear translocation. However, the precise mechanism underlying porf2 -induced alteration of $\mathrm{Wnt} / \beta$-catenin signaling needs to be fully elucidated.

As is reported in previous studies, GABAAR-mediated transmission regulates multiple steps of adult neurogenesis, including control of stem/precursor cell proliferation, cell fate decision, migration of precursor cells, survival of immature neurons, dendritic growth, and synaptogenesis (Platel et al., 2007; Ming and Song, 2011; Dieni et al., 2012). In the SGZ, NSCs respond tonically to GABA via the $\alpha 5 \beta 3 \gamma 2$ GABAAR composition to control their quiescent condition (Song et al., 2012). It is also reported that GABAARs containing the a4 subunit are expressed in typeI NSCs to control their proliferation rate (Duveau et al., 2011). Besides, Liu et al. reported that both the inter-neuron in the stem cell niche and the neuroblasts itself can release GABA, leading to tonic GABAAR activation of neural precursors and a decrease in proliferation (Liu et al., 2005). Still it is not clear how the signaling through GABAAR is processed in mediating NSC behavior. Interestingly, in our current study, we uncovered that a novel RhoGAP protein, porf-2 plays a inhibitory effect on NSC proliferation, suggesting its intrinsic role in maintaining stem cell quiescence as well as GABAAR. However, there are still questions unsolved. What's the upstream proteins or signals of porf-2? How is porf-2 regulated in the brain development or neurogenesis? Is it possible that GABAAR may function via Porf-2 and Rac1? Further study are needed to investigate whether porf- 2 may serve as a downstream effector 
of GABAAR or other membrane receptors to inhibit NSC proliferation.

In summary, our study demonstrates for the first time that porf-2 can inhibit NSC proliferation but has no effect on neuron/astrocyte differentiation of NSCs. And porf-2 inhibits NSC growth through its GAP domain by $\mathrm{Wnt} / \beta$-catenin pathway. From this point of views, the porf- 2 mediated signal pathway may provide us a new insight into its future applications in nerve system.

\section{AUTHOR CONTRIBUTIONS}

$\mathrm{GH}$ performed the experiments of morphology, histology, and biochemistry. GH, XY, KC, JX, and LG has been involved in analysis and interpretation of data and in drafting and revising the manuscript critically. LZ, HL, XL, and SZ set up the platform for $\mathrm{AAV}$ virus experiments and supervised the morphological analysis. DF designed experiments and revised the manuscript critically. All authors agree that all the questions related to the accuracy or integrity of the paper have been appropriately investigated and resolved, giving final approval of the version to be published.

\section{REFERENCES}

Ables, J. L., Breunig, J. J., Eisch, A. J., and Rakic, P. (2011). Not(ch) just development: Notch signalling in the adult brain. Nat. Rev. Neurosci. 12, 269-283. doi: 10.1038/nrn3024

Aertker, B. M., Bedi, S., and Cox, C. J. (2015). Strategies for CNS repair following TBI. Exp. Neurol. 275, 411-426. doi: 10.1016/j.expneurol.2015.01.008

Alvarez-Buylla, A., and Garcia-Verdugo, J. M. (2002). Neurogenesis in adult subventricular zone. J. Neurosci. 22, 629-634. Available online at: http:// www.jneurosci.org/content/22/3/629.short?sid=fbdb27ec-6535-4f73-bb06d948ca23c506

Bond, A. M., Ming, G. L., and Song, H. (2015). Adult mammalian neural stem cells and neurogenesis: five decades later. Cell Stem Cell 17, 385-395. doi: 10.1016/j.stem.2015.09.003

Bosco, E. E., Nakai, Y., Hennigan, R. F., Ratner, N., and Zheng, Y. (2010). NF2-deficient cells depend on the Rac1-canonical Wnt signaling pathway to promote the loss of contact inhibition of proliferation. Oncogene 29, 2540-2549. doi: 10.1038 /onc. 2010.20

Burns, A. J., and Thapar, N. (2014). Neural stem cell therapies for enteric nervous system disorders. Nat. Rev. Gastroenterol. Hepatol. 11, 317-328. doi: 10.1038/nrgastro.2013.226

Dasgupta, B., and Gutmann, D. H. (2005). Neurofibromin regulates neural stem cell proliferation, survival, and astroglial differentiation in vitro and in vivo. J. Neurosci. 25, 5584-5594. doi: 10.1523/JNEUROSCI.4693-04.2005

Deng, W., Aimone, J. B., and Gage, F. H. (2010). New neurons and new memories: how does adult hippocampal neurogenesis affect learning and memory? Nat. Rev. Neurosci. 11, 339-350. doi: 10.1038/nrn2822

Dieni, C. V., Chancey, J. H., and Overstreet-Wadiche, L. S. (2012). Dynamic functions of GABA signaling during granule cell maturation. Front. Neural Circuits 6:113. doi: 10.3389/fncir.2012.00113

Duveau, V., Laustela, S., Barth, L., Gianolini, F., Vogt, K. E., Keist, R., et al. (2011). Spatiotemporal specificity of GABAA receptor-mediated regulation of adult hippocampal neurogenesis. Eur. J. Neurosci. 34, 362-373. doi: 10.1111/j.14609568.2011.07782.x

Egeland, M., Zunszain, P. A., and Pariante, C. M. (2015). Molecular mechanisms in the regulation of adult neurogenesis during stress. Nat. Rev. Neurosci. 16, 189-200. doi: 10.1038/nrn3855

\section{ACKNOWLEDGMENTS}

This study was supported by the National Natural Science Foundation of China, 81171796 and 81401587.

\section{SUPPLEMENTARY MATERIAL}

The Supplementary Material for this article can be found online at: http://journal.frontiersin.org/article/10.3389/fncel. 2016.00085

Figure $\mathbf{S 1}$ | Porf-2 is expressed in NSCs of subgranular zone in DG. Expression of of porf-2, Sox-2, GFAP were visualized by immunolabeling with indicated antibody in DG area of brain slice. The boxes in left panel are shown at higher magnification in right panels. The white arrowhead indicated the colocalization of porf- 2 with GFAP ${ }^{+} /$Sox $-2^{+}$cell. Scale bars: $25 \mu \mathrm{m}$ in the left panel and $10 \mu \mathrm{m}$ in the right panel.

Figure S2 | Porf-2 was knocked down by shRNA. Porf-2 knock-down was confirmed by Western Blot analysis. The symbol* indicated the non-specific band smaller than $120 \mathrm{KD}$. GAPDH was used as a loading control.

Figure S3 | Rac1 DN showed the same phenotype as Porf-2 expression on NSC proliferation. Representative image of Edu positive cells in each group. The total NSC number was counted by DAPI. Quantification of the percentage of Edu positive cell number in each group. Scale bar: $50 \mu \mathrm{m}$. Data are mean \pm SEM $(n=$ 4). $* * P<0.01$ vs. control.

Esufali, S., and Bapat, B. (2004). Cross-talk between Rac1 GTPase and dysregulated Wnt signaling pathway leads to cellular redistribution of beta-catenin and TCF/LEF-mediated transcriptional activation. Oncogene 23, 8260-8271. doi: $10.1038 /$ si.onc. 1208007

Faigle, R., and Song, H. (2013). Signaling mechanisms regulating adult neural stem cells and neurogenesis. Biochim. Biophys. Acta. 1830, 2435-2448. doi: 10.1016/j.bbagen.2012.09.002

Gage, F. H. (2000). Mammalian neural stem cells. Science 287, 1433-1438. doi: $10.1126 /$ science.287.5457.1433

Homem, C. C., Repic, M., and Knoblich, J. A. (2015). Proliferation control in neural stem and progenitor cells. Nat. Rev. Neurosci. 16, 647-659. doi: $10.1038 / \mathrm{nrn} 4021$

Horner, P. J., and Gage, F. H. (2000). Regenerating the damaged central nervous system. Nature 407, 963-970. doi: 10.1038/35039559

Hsieh, J. (2012). Orchestrating transcriptional control of adult neurogenesis. Genes Dev. 26, 1010-1021. doi: 10.1101/gad.187336.112

Hu, H., Li, M., Labrador, J. P., McEwen, J., Lai, E. C., Goodman, C. S., et al. (2005). Cross GTPase-activating protein (CrossGAP)/Vilse links the Roundabout receptor to Rac to regulate midline repulsion. Proc. Natl. Acad. Sci. U.S.A. 102, 4613-4618. doi: 10.1073/pnas.0409325102

Hu, S. B., and Nowak, F. V. (1994). Regional distinction in age-related changes of preoptic regulatory factor- 1 and preoptic regulatory factor- 2 mRNA expression in the rat brain. Mol. Cell. Neurosci. 5, 376-381. doi: 10.1006/mcne.19 94.1045

Kahn, M. (2014). Can we safely target the WNT pathway? Nat. Rev. Drug Discov. 13, 513-532. doi: $10.1038 / \mathrm{nrd} 4233$

Kempermann, G., and Gage, F. H. (1999). New nerve cells for the adult brain. Sci. Am. 280, 48-53. doi: 10.1038/scientificamerican0599-48

Kerber, M. L., and Cheney, R. E. (2011). Myosin-X: a MyTH-FERM myosin at the tips of filopodia. J. Cell Sci. 124(Pt 22), 3733-41. doi: 10.1242/jcs. 023549

Koehl, M., and Abrous, D. N. (2011). A new chapter in the field of memory: adult hippocampal neurogenesis. Eur. J. Neurosci. 33, 1101-1114. doi: 10.1111/j.1460-9568.2011.07609.x

Lim, J., Ritt, D. A., Zhou, M., and Morrison, D. K. (2014). The CNK2 scaffold interacts with vilse and modulates Rac cycling during spine morphogenesis in hippocampal neurons. Curr. Biol. 24, 786-792. doi: 10.1016/j.cub.2014.02.036 
Liu, A., and Niswander, L. A. (2005). Bone morphogenetic protein signalling and vertebrate nervous system development. Nat. Rev. Neurosci. 6, 945-954. doi: $10.1038 / \mathrm{nrn} 1805$

Liu, X., Wang, Q., Haydar, T. F., and Bordey, A. (2005). Nonsynaptic GABA signaling in postnatal subventricular zone controls proliferation of GFAPexpressing progenitors. Nat. Neurosci. 8, 1179-1187. doi: 10.1038/nn1522

Louis, S. A., and Reynolds, B. A. (2005). Generation and differentiation of neurospheres from murine embryonic day 14 central nervous system tissue. Methods Mol. Biol. 290, 265-280. doi: 10.1385/1-59259-838-2:265

Louvi, A., and Artavanis-Tsakonas, S. (2006). Notch signalling in vertebrate neural development. Nat. Rev. Neurosci. 7, 93-102. doi: 10.1038/nrn1847

Lu, Q., Li, J., and Zhang, M. (2014). Cargo recognition and cargo-mediated regulation of unconventional myosins. Acc. Chem. Res. 47, 3061-3070. doi: $10.1021 / \operatorname{ar} 500216 z$

Lundstrom, A., Gallio, M., Englund, C., Steneberg, P., Hemphala, J., Aspenstrom, P., et al. (2004). Vilse, a conserved Rac/Cdc42 GAP mediating Robo repulsion in tracheal cells and axons. Genes Dev. 18, 2161-2171. doi: 10.1101/gad. 310204

Ma, S., and Nowak, F. V. (2011). The RhoGAP domain-containing protein, Porf2, inhibits proliferation and enhances apoptosis in neural stem cells. Mol. Cell. Neurosci. 46, 573-582. doi: 10.1016/j.mcn.2010.12.008

Marin-Burgin, A., and Schinder, A. F. (2012). Requirement of adult-born neurons for hippocampus-dependent learning. Behav. Brain Res. 227, 391-399. doi: 10.1016/j.bbr.2011.07.001

McKay, R. (1997). Stem cells in the central nervous system. Science. 276, 66-71. doi: 10.1126/science. 276.5309 .66

Ming, G. L., and Song, H. (2011). Adult neurogenesis in the mammalian brain: significant answers and significant questions. Neuron 70, 687-702. doi: 10.1016/j.neuron.2011.05.001

Mongiat, L. A., and Schinder, A. F. (2011). Adult neurogenesis and the plasticity of the dentate gyrus network. Eur. J. Neurosci. 33, 1055-1061. doi: 10.1111/j.14609568.2011.07603.x

Muller, F. J., Snyder, E. Y., and Loring, J. F. (2006). Gene therapy: can neural stem cells deliver? Nat. Rev. Neurosci. 7, 75-84. doi: 10.1038/nrn1829

Nakamura, M., and Okano, H. (2013). Cell transplantation therapies for spinal cord injury focusing on induced pluripotent stem cells. Cell Res. 23, 70-80. doi: $10.1038 /$ cr.2012.171

Nowak, F. V. (1990). Cloning of two hypothalamic cDNAs encoding tissue-specific transcripts in the preoptic area and testis. Mol. Endocrinol. 4, 1205-1210. doi: 10.1210/mend-4-8-1205

Nowak, F. V. (1997). Modulation of preoptic regulatory factor-2 (porf-2) mRNAs by castration and hypophysectomy. Endocrine 6, 213. doi: 10.1007/BF02738968

Nowak, F. V. (2003). Expression and characterization of the preoptic regulatory factor-1 and -2 peptides. Regul. Pept. 115, 179-185. doi: 10.1016/S01670115(03)00174-5

Platel, J. C., Lacar, B., and Bordey, A. (2007). GABA and glutamate signaling: homeostatic control of adult forebrain neurogenesis. J. Mol. Histol. 38, 303-311. doi: $10.1007 / \mathrm{s} 10735-007-9103-8$

Pluchino, S., and Martino, G. (2008). The therapeutic plasticity of neural stem/precursor cells in multiple sclerosis. J. Neurol. Sci. 265, 105-110. doi: 10.1016/j.jns.2007.07.020

Reynolds, B. A., and Weiss, S. (1992). Generation of neurons and astrocytes from isolated cells of the adult mammalian central nervous system. Science 255, 1707-1710. doi: 10.1126/science. 1553558

Rolfe, A., and Sun, D. (2015). "Stem cell therapy in brain trauma: implications for repair and regeneration of injured brain in experimental TBI models." in Brain Neurotrauma: Molecular, Neuropsychological, and Rehabilitation Aspects, Chapter 42, eds F. H. Kobeissy and S. W. Hoffman (Boca Raton, FL: CRC Press/Taylor \& Francis), 587-596.

Rossi, F., and Cattaneo, E. (2002). Opinion: neural stem cell therapy for neurological diseases: dreams and reality. Nat. Rev. Neurosci. 3, 401-409. doi: $10.1038 / \mathrm{nrn} 809$
Schwarz, T. J., Ebert, B., and Lie, D. C. (2012). Stem cell maintenance in the adult mammalian hippocampus: a matter of signal integration? Dev. Neurobiol. 72, 1006-1015. doi: 10.1002/dneu.22026

Selden, N. R. (2008). Stem cells and central nervous system therapeutics. Neurosurg. Focus 24, E2. doi: 10.3171/FOC/2008/24/3-4/E1

Shimazaki, T. (2003). Biology and clinical application of neural stem cells. Horm. Res. 60(Suppl, 3), 1-9. doi: 10.1159/000074492

Snyder, J. S., Kee, N., and Wojtowicz, J. M. (2001). Effects of adult neurogenesis on synaptic plasticity in the rat dentate gyrus. J. Neurophysiol. 85, 2423-2431. Available online at: http://jn.physiology.org/content/85/6/2423.long

Song, J., Zhong, C., Bonaguidi, M. A., Sun, G. J., Hsu, D., Gu, Y., et al. (2012). Neuronal circuitry mechanism regulating adult quiescent neural stem-cell fate decision. Nature 489, 150-154. doi: 10.1038/nature11306

Suh, H., Deng, W., and Gage, F. H. (2009). Signaling in adult neurogenesis. Annu. Rev. Cell Dev. Biol. 25, 253-275. doi: 10.1146/annurev.cellbio.042308.113256

Sun, T., and Hevner, R. F. (2014). Growth and folding of the mammalian cerebral cortex: from molecules to malformations. Nat. Rev. Neurosci. 15, 217-232. doi: $10.1038 / \mathrm{nrn} 3707$

Tcherkezian, J., and Lamarche-Vane, N. (2007). Current knowledge of the large RhoGAP family of proteins. Biol. Cell 99, 67-86. doi: 10.1042/BC20060086

Teng, Y. D., Lavik, E. B., Qu, X., Park, K. I., Ourednik, J., Zurakowski, D., et al. (2002). Functional recovery following traumatic spinal cord injury mediated by a unique polymer scaffold seeded with neural stem cells. Proc. Natl. Acad. Sci. U.S.A. 99, 3024-3029. doi: 10.1073/pnas.052678899

Tong, L. M., Fong, H., and Huang, Y. (2015). Stem cell therapy for Alzheimer's disease and related disorders: current status and future perspectives. Exp. Mol. Med. 47:e151. doi: 10.1038/emm.2014.124

Upadhyay, G., Goessling, W., North, T. E., Xavier, R., Zon, L. I., and Yajnik, V. (2008). Molecular association between beta-catenin degradation complex and Rac guanine exchange factor DOCK4 is essential for Wnt/beta-catenin signaling. Oncogene 27, 5845-5855. doi: 10.1038/onc.2008.202

Varela-Nallar, L., and Inestrosa, N. C. (2013). Wnt signaling in the regulation of adult hippocampal neurogenesis. Front. Cell. Neurosci. 7:100. doi: $10.3389 /$ fncel.2013.00100

Wu, X., Tu, X., Joeng, K. S., Hilton, M. J., Williams, D. A., and Long, F. (2008). Rac1 activation controls nuclear localization of beta-catenin during canonical Wnt signaling. Cell 133, 340-353. doi: 10.1016/j.cell.2008.01.052

Yang, X. T., Bi, Y. Y., Chen, E. T., and Feng, D. F. (2014). Overexpression of Wnt3a facilitates the proliferation and neural differentiation of neural stem cells in vitro and after transplantation into an injured rat retina. J. Neurosci. Res. 92, 148-161. doi: 10.1002/jnr.23314

Yoon, K., and Gaiano, N. (2005). Notch signaling in the mammalian central nervous system: insights from mouse mutants. Nat. Neurosci. 8, 709-715. doi: $10.1038 / \mathrm{nn} 1475$

Zhao, C., Deng, W., and Gage, F. H. (2008). Mechanisms and functional implications of adult neurogenesis. Cell 132, 645-660. doi: 10.1016/j.cell.2008.01.033

Zhao, C., Teng, E. M., Summers, R. J., Ming, G. L., and Gage, F. H. (2006). Distinct morphological stages of dentate granule neuron maturation in the adult mouse hippocampus. J. Neurosci. 26, 3-11. doi: 10.1523/JNEUROSCI.3648-05.2006

Conflict of Interest Statement: The authors declare that the research was conducted in the absence of any commercial or financial relationships that could be construed as a potential conflict of interest.

Copyright (ङ 2016 Huang, Yang, Chen, Xing, Guo, Zhu, Li, Li, Zhang and Feng. This is an open-access article distributed under the terms of the Creative Commons Attribution License (CC BY). The use, distribution or reproduction in other forums is permitted, provided the original author(s) or licensor are credited and that the original publication in this journal is cited, in accordance with accepted academic practice. No use, distribution or reproduction is permitted which does not comply with these terms. 